\title{
ON THE NUMBER OF $\alpha$-LABELED GRAPHS
}

\author{
Christian BARrientos \\ AND \\ SARAH Minion \\ Department of Mathematics \\ Clayton State University \\ Morrow, Georgia 30260, USA \\ e-mail: chr_barrientos@yahoo.com \\ sarah.m.minion@gmail.com
}

\begin{abstract}
When a graceful labeling of a bipartite graph places the smaller labels in one of the stable sets of the graph, it becomes an $\alpha$-labeling. This is the most restrictive type of difference-vertex labeling and it is located at the very core of this research area. Here we use an extension of the adjacency matrix to count and classify $\alpha$-labeled graphs according to their size, order, and boundary value.
\end{abstract}

Keywords: $\alpha$-labeling, $\alpha$-graph, graceful triangle.

2010 Mathematics Subject Classification: 05C30, 05C78.

\section{REFERENCES}

[1] B.D. Acharya and S.M. Hegde, On certain vertex valuations of a graph, Indian J. Pure Appl. Math. 22 (1991) 553-560.

[2] V. Ajtha, S. Arumugam and K.A. Germina, On square sum graphs, AKCE Int. J. Graphs Comb. 6 (2009) 1-10.

[3] M. Bača and C. Barrientos, Graceful and edge-antimagic labelings, Ars Combin. 96 (2010) 505-513.

[4] C. Barrientos and E. Krop, Mean graphs, AKCE Int. J. Graphs Comb. 11 (2014) $13-26$.

[5] C. Barrientos and S. Minion, Enumerating families of labeled graphs, J. Integer Seq. 18 (2015) 15.1.7. 
[6] C. Barrientos and S. Minion, Three graceful operations, J. Algorithms Comput. 45 (2014) 13-24.

[7] C. Bu and J. Zhang, The properties of $(k, d)$-graceful graphs, preprint (2014).

[8] G.J. Chang, D.F. Hsu and D.G. Rogers, Additive variations on a graceful theme: some results on harmonious and other related graphs, Proceedings of the Twelfth Southeastern Conference on Combinatorics, Graph Theory and Computing, Vol. I (Baton Rouge, LA., 1981), Congr. Numer. 32 (1981) 181-197.

[9] G. Chartrand and L. Lesniak, Graphs and Digraphs (Wadsworth and Brooks/Cole, 1986).

[10] W.C. Chen, H.I. Lü and Y.N. Yeh, Operations of interlaced trees and graceful trees, Southeast Asian Bull. Math. 21 (1997) 337-348.

[11] R. Figueroa-Centeno, R. Ichishima and F. Muntaner-Batle, The place of super edgemagic labelings among other classes of labelings, Discrete Math. 231 (2001) 153-168.

doi:10.1016/S0012-365X(00)00314-9

[12] H. Fukś and L. Sullivan, Numeration of number-conserving cellular automata rules with two inputs, J. Cell. Autom. 2 (2007) 141-148.

[13] J.A. Gallian, A dynamic survey of graph labeling, Electron. J. Combin. (2015) \#DS6.

[14] R.B. Gnanajothi, Topics in Graph Theory (Ph.D. Thesis, Madurai Kamaraj University, 1991).

[15] T. Grace, On sequential labelings of graphs, J. Graph Theory 7 (1983) 195-201. doi:10.1002/jgt.3190070208

[16] D. Jungreis and M. Reid, Labeling grids, Ars Combin. 34 (1992) 167-182.

[17] M. Maheo and H. Thuillier, On d-graceful graphs, Ars Combin. 13 (1982) 181-192.

[18] OEIS Foundation Inc., The Online Encyclopedia of Integer Sequences (2015). http://oeis.org

[19] D.A. Sheppard, The factorial representation of major balanced graphs, Discrete Math. 15 (1976) 379-388. doi:10.1016/0012-365X(76)90051-0

[20] C.-L. Shiue and H.-C. Lu, Trees which admit no $\alpha$-labelings, Ars Combin. 103 (2012) 453-463.

[21] Y. Yuansheng, X. Yue, X. Xirong and M. Xinhong, Super edge magic labelings of book graphs, Ars Combin. 93 (2009) 431-438.

Received 13 April 2015

Revised 28 October 2016

Accepted 28 October 2016 